\title{
Proteomic and metabolic profile analysis of low-temperature storage responses in Ipomoea batata Lam. tuberous roots
}

\author{
Peng Cui, Yongxin Li, Chenke Cui, Yanrong Huo, Guoquan Lu and Huqing Yang* (1)
}

\begin{abstract}
Background: Sweetpotato (Ipomoea batatas L.) is one of the seven major food crops grown worldwide. Cold stress often can cause protein expression pattern and substance contents variations for tuberous roots of sweetpotato during low-temperature storage. Recently, we developed proteometabolic profiles of the fresh sweetpotatoes (cv. Xinxiang) in an attempt to discern the cold stress-responsive mechanism of tuberous root crops during post-harvest storage.

Results: For roots stored under $4^{\circ} \mathrm{C}$ condition, the $\mathrm{Cl}$ index, REC and MDA content in roots were significantly higher than them at control temperature $\left(13^{\circ} \mathrm{C}\right)$. The activities of SOD, CAT, APX, $\mathrm{O}_{2}{ }^{-}$producing rate, proline and especially soluble sugar contents were also significantly increased. Most of the differentially expressed proteins (DEPs) were implicated in pathways related to metabolic pathway, especially phenylpropanoids and followed by starch and sucrose metabolism. L-ascorbate peroxidase 3 and catalase were down-regulated during low temperature storage. a-amylase, sucrose synthase and fructokinase were significantly up-regulated in starch and sucrose metabolism, while $\beta$-glucosidase, glucose-1-phosphate adenylyl-transferase and starch synthase were opposite. Furthermore, metabolome profiling revealed that glucosinolate biosynthesis, tropane, piperidine and pyridine alkaloid biosynthesis as well as protein digestion and absorption played a leading role in metabolic pathways of roots. Leucine, tryptophan, tyrosine, isoleucine and valine were all significantly up-regulated in glucosinolate biosynthesis.
\end{abstract}

Conclusions: Our proteomic and metabolic profile analysis of sweetpotatoes stored at low temperature reveal that the antioxidant enzymes activities, proline and especially soluble sugar content were significantly increased. Most of the DEPs were implicated in phenylpropanoids and followed by starch and sucrose metabolism. The discrepancy between proteomic (L-ascorbate peroxidase 3 and catalase) and biochemical (CAT/APX activity) data may be explained by higher $\mathrm{H}_{2} \mathrm{O}_{2}$ levels and increased ascorbate redox states, which enhanced the CAT/APX activity indirectly. Glucosinolate biosynthesis played a leading role in metabolic pathways. Leucine, tryptophan, tyrosine, isoleucine and valine were all significantly up-regulated in glucosinolate biosynthesis.

Keywords: Sweetpotato, Low-temperature storage, Proteometabolomic, Starch metabolism, Chilling tolerance

* Correspondence: yanghuqing@sohu.com

School of Agriculture and Food Science, Zhejiang Agriculture \& Forestry

University, Hangzhou 311300, China

(c) The Author(s). 2020 Open Access This article is licensed under a Creative Commons Attribution 4.0 International License, which permits use, sharing, adaptation, distribution and reproduction in any medium or format, as long as you give appropriate credit to the original author(s) and the source, provide a link to the Creative Commons licence, and indicate if changes were made. The images or other third party material in this article are included in the article's Creative Commons licence, unless indicated otherwise in a credit line to the material. If material is not included in the article's Creative Commons licence and your intended use is not permitted by statutory regulation or exceeds the permitted use, you will need to obtain permission directly from the copyright holder. To view a copy of this licence, visit http://creativecommons.org/licenses/by/4.0/. The Creative Commons Public Domain Dedication waiver (http://creativecommons.org/publicdomain/zero/1.0/) applies to the data made available in this article, unless otherwise stated in a credit line to the data. 


\section{Background}

Sweetpotato (Ipomoea batatas L.), a dicotyledonous plant which belongs to the Convolvulaceae family, ranks as the seventh-most important food crop in the world. As a major nutrition organ, storage root (SR) possessed a mass content of starch and photoassimilate. Starch accounts for $50-80 \%$ proportion of the dry matter in the SR $[1,2]$. Since soluble sugar content is very low in freshly harvested roots during general production process, a certain time of post-harvest storage at 13$15^{\circ} \mathrm{C}$ is imperative to facilitate starch-sugar interconversion and boost the sweetness to increase the tuberous food quality before sale. It is noticeable that exposure to $5^{\circ} \mathrm{C}$ for $20 \mathrm{~d}$ has been observed to increase sweetness of 'Kokei 14' roots, however, this treatment also caused rottenness and high rate of carbohydrate loss [3]. Therefore, a better understanding of biochemical and molecular response mechanisms to chilling stress is essential for extending tuberous crops storage time under low temperature condition.

Compared with model plants, it is more difficult for sweetpotatoes to find out genes implicated in various stress tolerance because of its complicated genetic background. Although some genomic [4,5] and proteomic [6-8] resources of sweetpotatoes have been available now, these pieces of information are still limited to explicate the molecular mechanism of chilling resistant. With the development of sequencing technique, metabolomics has been considered as a powerful complementary tool to acquire the biological information associated with the metabolites. Metabolites are not only the endproducts of expressions of some genes, but also the consequence of interaction between the genome and its milieu. Therefore, it is probable to envisage the functional genomics assembly by connecting gene expression to the metabolomic knowledge [9].

As a chilling-sensitive tropical crop, sweetpotatoes can be irreparably damaged when the temperature drops below $10^{\circ} \mathrm{C}$. A main reason for this is oxidative injuries caused by an increased accumulation of reactive oxygen species (ROS) [10-16]. In plants, stress-induced ROS scavenging is usually implemented by both enzymatic and non-enzymatic low molecular metabolic antioxidants $[17,18]$. As we all know, the starch content in fresh roots of sweetpotatoes is about $15-30 \%$ [8]. Soluble sugar not only serves as substrates for starch production, but also may also function as a signal involved in chilling defense for tubers.

To better explore the proteins and metabolic pathways under chilling condition, we carried out the proteometabolomic profile of fresh sweetpotatoes to clarify the cold stress-responsive mechanism. Integration of proteomic and metabolomic profiles information would give new insights into the molecular functions of tuberous root crops during post-harvest storage. This would provide a basis for future comparative proteomic efforts for this important crop including gene discovery and improvement of chilling stress tolerance.

\section{Results \\ Morphological variations under cold storage}

To investigate the effect of chilling stress on the storage of sweetpotatoes, freshy harvested ones (cv. Xinxiang) were stored in the storage chamber of $13^{\circ} \mathrm{C}(\mathrm{CK})$ and $4{ }^{\circ} \mathrm{C}$ for 14 days (d). As shown in Fig. 1 and Table 1 , roots at $13{ }^{\circ} \mathrm{C}$ showed no chilling injury (CI) symptoms, while the epidermis of roots exposed to $4{ }^{\circ} \mathrm{C}$ (Fig. 1b) were significantly spotted and shriveled than those stored at $13{ }^{\circ} \mathrm{C}$ (Fig. 1a). The CI index was also significantly higher than that of control roots. In addition, the water content exhibited significantly decreases under $13^{\circ} \mathrm{C}$, and no differences were found under low temperature $\left(4^{\circ} \mathrm{C}\right)$.

\section{Effects of low-temperature storage on oxidative stress}

The relative electrical conductivity (REC) level and malondialdehyde (MDA) content were significantly higher in the roots exposed to $4{ }^{\circ} \mathrm{C}$ condition than that at $13{ }^{\circ} \mathrm{C}$ (Fig. 2). The activities of SOD, CAT, APX, $\mathrm{O}_{2}{ }^{--}$producing rate, proline and soluble sugar contents have been shown in Fig. 3. Similarly, the low temperature $\left(4^{\circ} \mathrm{C}\right)$ significantly increased the activities of antioxidant enzymes (Fig. 3a, b, c) and the production rate of $\mathrm{O}_{2}^{--}$(Fig. 3d). Moreover, chilling stress also enhanced the proline (Fig. 3e), glucose, fructose and sucrose (Fig. 3f) contents. It's worth mentioning that three types of soluble sugar contents were increased most among above of physiological indexes, by $112.4,145.6$ and $139.4 \%$, respectively.

\section{Segregation and identification of proteins}

Compared to the control, 266 and 158 proteins were found significantly up- and down-regulated by $>1.5$ fold, respectively in roots under $4{ }^{\circ} \mathrm{C}$ storage (Supplementary Table S2, Additional file 1 and Additional file 2). The protein bands were clear, uniform and not degraded in each lane (Supplementary Figure S1). The molecular masses of identified proteins were distributed 5-275 $\mathrm{kDa}$, with majority of proteins (96\%) distributed in the range of $<100 \mathrm{kDa}$ (Supplementary Figure S2). The extracted proteins were suitable for further LC-MS/MS analysis.

\section{Annotation of DEPs in GO classification, subcellular localization and pathway enrichment}

Annotation of differentially expressed protein (DEPs) function and their cellular location is necessary to understand their roles at molecular level (Additional file 3). The results demonstrated that they were grouped into 15 


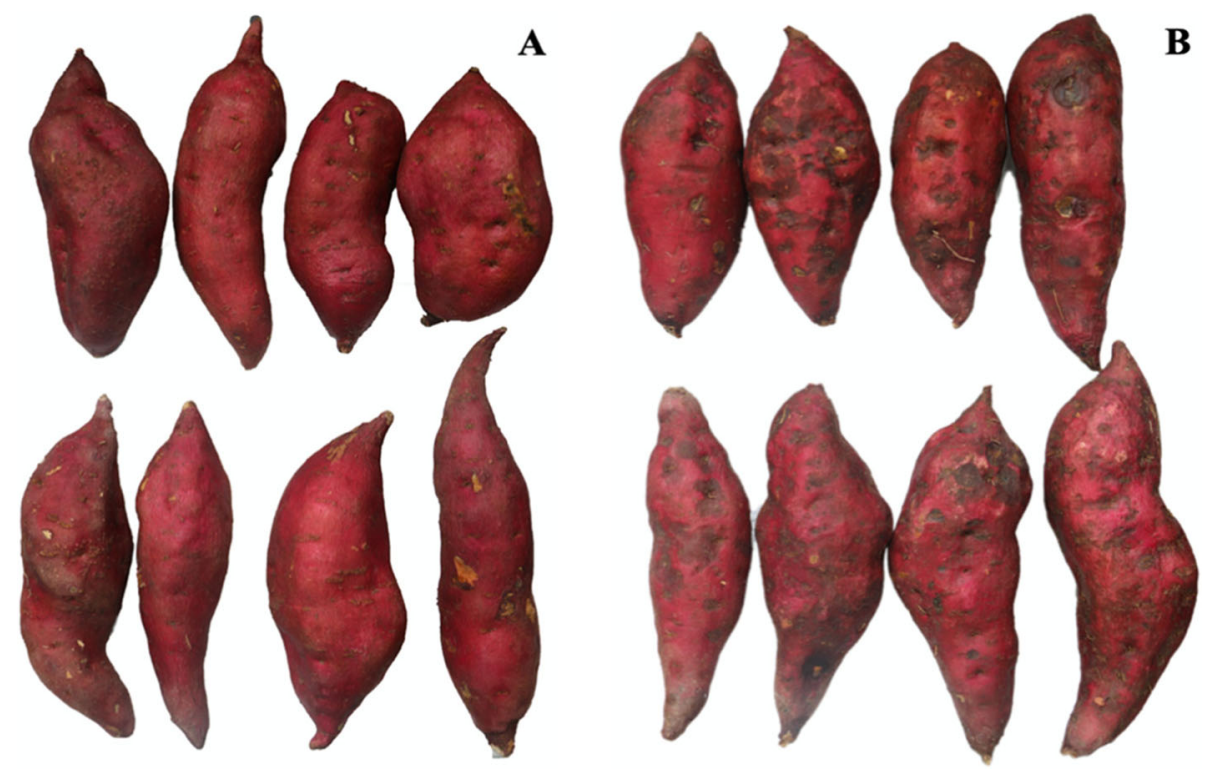

Fig. 1 Morphological differences in tuber shape and color during storage at $13^{\circ} \mathrm{C}(\mathbf{a})$ and $4^{\circ} \mathrm{C}(\mathbf{b})$ for $14 \mathrm{~d}$

distinct categories. These proteins were mainly implicated in metabolic processes, cellular components, catalytic activities and binding (Fig. 4a, b, c). Most of them were associated with catalytic activities $(\sim 47 \%)$, followed by binding $(\sim 43 \%)$, metabolic process $(\sim 40 \%)$, cell $(\sim 34 \%)$ and organelle $(\sim 23 \%)$.

In addition, the DEPs were delegated based on their presence in a particular compartment (Additional file 4). Most of them were localized in the chloroplast/cytoplasm $(\sim 30 \%)$, followed by nucleus $(\sim 15 \%)$ and plasma membrane ( 5\%) (Fig. 4d).

The identified proteins were further analyzed via KEGG database for interpretation of their involvement in different metabolic pathways (Additional file 5). Most of the DEPs were implicated in pathways related to metabolic pathway $(\sim 22 \%)$, followed by biosynthesis of secondary metabolites $(\sim 16 \%)$, and phenylpropanoid biosynthesis (Fig. 4e).

\section{DEPs involved in phenylpropanoid biosynthesis}

As previously mentioned, most of proteins were involved in metabolic pathway and biosynthesis of secondary metabolites. Phenolic compounds regulated by phenylalanine ammonia lyase (PAL), cinnamyl alcohol

Table $1 \mathrm{Cl}$ index and water content of sweetpotatoes after storage at different temperatures

\begin{tabular}{llllll}
\hline $\begin{array}{lllll}\text { Storage } \\
\text { time (d) }\end{array}$ & \multicolumn{2}{c}{$\mathrm{Cl}$ index } & & \multicolumn{2}{c}{ Water content (\%FW) } \\
\cline { 2 - 3 } \cline { 6 - 7 } & $\mathbf{1 3}{ }^{\circ} \mathbf{C}$ & $\mathbf{4}^{\circ} \mathbf{C}$ & & $\mathbf{1 3}{ }^{\circ} \mathbf{C}$ & $\mathbf{4}^{\circ} \mathbf{C}$ \\
\hline 0 & $0.0 \pm 0.0 \mathrm{a}$ & $0.0 \pm 0.0 \mathrm{~b}$ & & $64.5 \pm 2.5 \mathrm{a}$ & $64.5 \pm 3.1 \mathrm{a}$ \\
14 & $0.0 \pm 0.0 \mathrm{a}$ & $0.7 \pm 0.1 \mathrm{a}$ & & $60.7 \pm 1.6 \mathrm{~b}$ & $64 \pm 2.7 \mathrm{a}$ \\
\hline
\end{tabular}

dehydrogenase (CAD), Hydroxycinnamoyl transferase (HCT) were listed in Table 2. The $p$ value of these proteins was negatively corelated with their significances in phenylpropanoid biosynthesis pathway. Hence, the significance order of DEPs was shikimate>peroxidase $4>4$ coumarate-CoA ligase $>$ Cytochrome P450 (cytochrome P450 monooxygenases) $>$ PAL $>$ CAD .

\section{Differential multiple of the DEPs participated in starch and sucrose metabolism}

As compared to the roots stored at $13^{\circ} \mathrm{C}$, there were 11 DEPs participated in starch and sucrose metabolism under $4{ }^{\circ} \mathrm{C}$ (Fig. 5). The filtered $p$ value matrix $(p<0.05)$ transformed by the function $\mathrm{x}=-\lg$ ( $p$ value) was conduct to evaluate the celesius4/celesius13 ratio, which was positively corelated with the differential multiple of DEPs. Three proteins $(x>1.5)$ were up regulated, while others $(\mathrm{x}<1.5)$ presented an opposite trend in this metabolic pathway. The ratio of sucrose synthase (P11) and $\beta$-glucosidase (P3) was 7.19 and 0.56 , significantly higher and lower than other proteins, respectively (Fig. 5).

\section{Functional network of the DEPs in starch and sucrose metabolism}

The functional network under chilling stress for roots was illustrated in Fig. 6. There were three up- and three down-regulated DEPs. $\alpha$-amylase (EC: 3.2.1.1, red), associated with starch metabolism and carbohydrate digestion or absorption, was significantly up-regulated when maltodextrin or starch was hydrolyzed to maltose. Furthermore, it was homologous with K01177 ( $\beta$-amylase: EC: 3.2.1.2), K05992 (maltogenic $\alpha$-amylase: EC: 

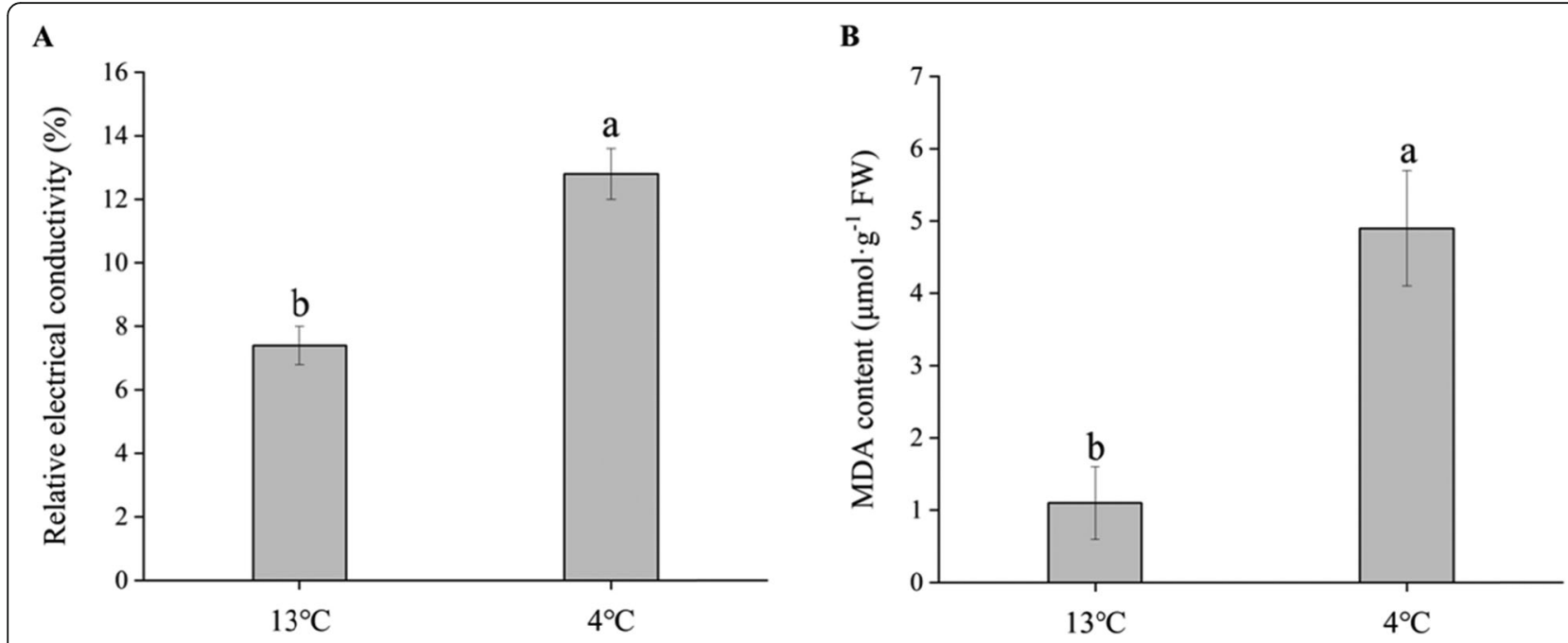

Fig. 2 Effects of low-temperature storage on relative electrical conductivity (REC) and MDA content in sweetpotato roots for $14 \mathrm{~d}$. a Relative electrical conductivity. $\mathbf{b}$ MDA content. Vertical bars represent the mean \pm SE. Different letters indicate statistically significant differences $(p<0.05)$ by LSD test

3.2.1.133) in terms of the orthology analysis. Similarly, both of EC: 2.4.1.13 (sucrose synthase) and EC: 2.7.1.4 (fructokinase) were significantly up-regulated in amino and nucleotide sugar metabolism. On the other hand, EC: 3.2.1.21, EC: 2.7.7.27 and EC: 2.4.1.21 proteins, named as $\beta$-glucosidase, glucose-1-phosphate adenylyltransferase and starch synthase, respectively, were significantly down-regulated in starch and sucrose metabolism pathway. They were mainly involved in phenylpropanoid biosynthesis, biosynthesis of starch and secondary metabolites as well as polysaccharide accumulation. The degradation of starch into soluble sugar can not only boost the sweetness, but also significantly improve the resistance to chilling stress.

\section{Metabolome profiling and its fold change analysis}

The metabolome profiling of sweetpotato tubers led to the identification of 76 differentially expressed metabolites (DEMs) in the roots stored at $4{ }^{\circ} \mathrm{C}$ as compared to them at $13{ }^{\circ} \mathrm{C}$. There were 31 up- and 45 downregulated metabolites (Supplementary Table S3 and Additional file 6). The absolute value level of fold change (FC) was closely related to significance of the metabolic component. The results (Fig. 7) showed that the absolute $\log _{2} \mathrm{FC}$ values of 4 components in up-regulated metabolites were more than 10.00, including glutaric acid (16.69), followed by 3-hydroxy-3-methylpentane-1,5dioic acid (14.97), apigenin O-malonylhexoside (14.1) and apigenin 7-O-glucoside (cosmosiin) (13.56). Nevertheless, the absolute values of 9 components were more than 10 in down-regulated DEMs, namely sinapoylcholine (14.38), D-glucoronic acid (14.08), N-acetyl-5- hydroxytryptamine (14.5), 5-Methylcytosine (13.32) etc. The metabolic activities of a large proportion of identified components dropped off in roots under $4{ }^{\circ} \mathrm{C}$.

\section{Screening and distribution of DEMs in roots under chilling stress}

Compared to the absolute value level of fold change, Variable Importance in Project (VIP) value $(>1)$ was extremely associated with the significance of metabolic compound in the corresponding class. All the identified DEMs were categorized into 20 classes. Most of them ( $\sim 33 \%)$ were belonging to nucleotide, its derivates and amino acid derivatives group. On the basis of VIP and $\log _{2} \mathrm{FC}$ value, the results (Table 3 ) illustrated that most of components were down-regulated except 3-hydroxy3-methylpentane-1,5-dioic acid and glutaric acid. The VIP and $\log _{2}$ FC value of glutaric acid, belonged to organic acids, were the highest (4.01 and 16.69, respectively), followed by D-glucoronic acid (3.69 and 14.08), $\mathrm{N}$-acetyl-5-hydroxytryptamine (3.66 and 14.05) and 5Methylcytosine (3.58 and 13.32) (Table 3 and Fig. 8a). Carbohydrates were represented by D-glucoronic acid, which was an important member of sugar metabolism.

Furthermore, KEGG pathway enrichment was conducted in terms of their $P$-values and rich factors. Pvalue and rich factor had negative and positive correlation with enrichment significance of metabolic compounds, respectively. The P-value of glucosinolate biosynthesis, tropane, piperidine and pyridine alkaloid biosynthesis $\left(9.94 \times 10^{-3}\right)$ was obviously lower than protein digestion and absorption $\left(3.56 \times 10^{-2}\right)$ (Table 4 and Fig. 8b). 

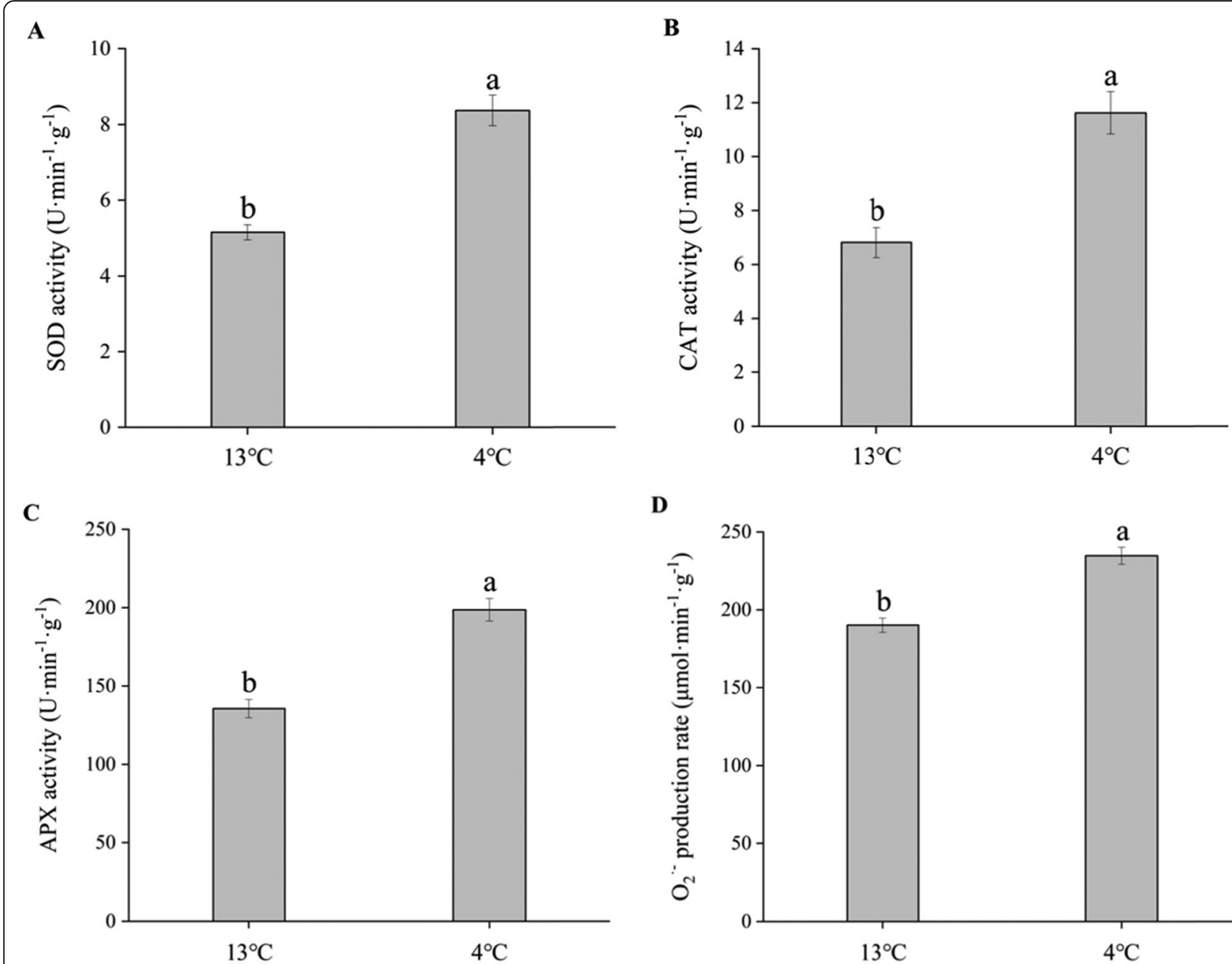

D
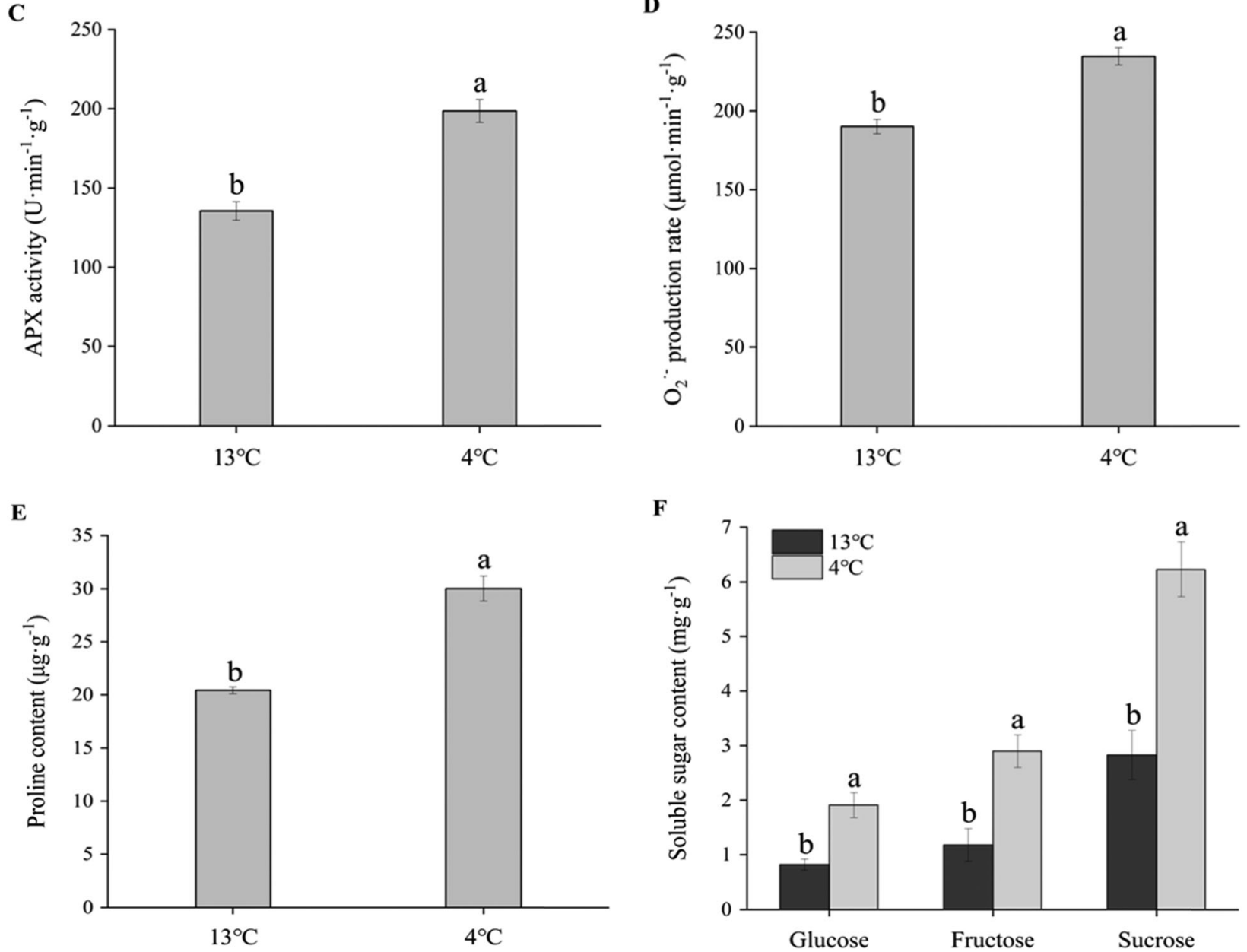

Fig. 3 Effect of low-temperature storage on oxidative stress in terms of SOD (a), CAT (b), APX (c) activities, $\mathrm{O}_{2}^{-}$producing rate (d), proline content (e) and soluble sugar content (f) such as glucose, fructose, and sucrose in sweetpotatoes for $14 \mathrm{~d}$. Vertical bars represent the mean \pm SE. Different letters indicate statistically significant differences $(p<0.05)$ by the LSD test 


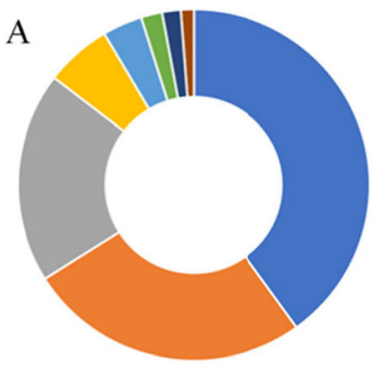

- metabolic process

" single-organism process

" cellular process

" response to stimulus

" localization

" biological regulation

- cellular component organization

" signaling

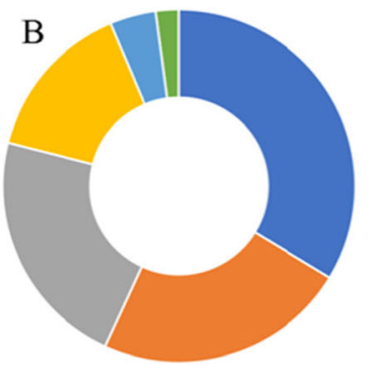

- cell

" organelle

"membrane

" macromolecular complex

" supramolecular complex

" extracellular region

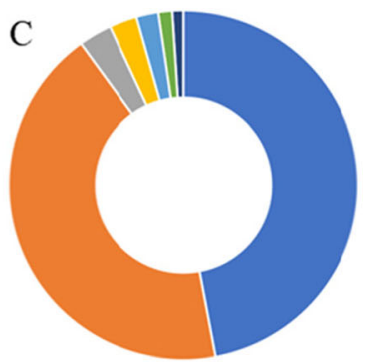

- catalytic activity

" binding

" molecular function regulator

" antioxidant activity

- structural molecule activity

" transporter activity

" other

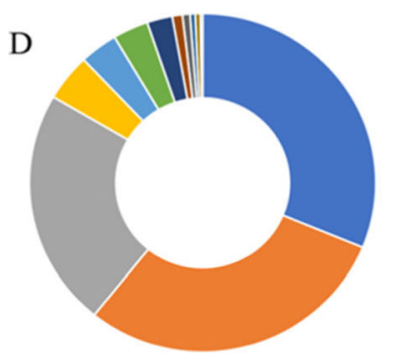

= chloroplas

= cytoplasm

" nucleus
" plasma membrane

= extracellular

= mitochondria

- cytoskeleton

- endoplasmic reticulum

- vacuolar membrane

- nucleus,plasma membrane

- peroxisome

- chloroplast,mitochondria

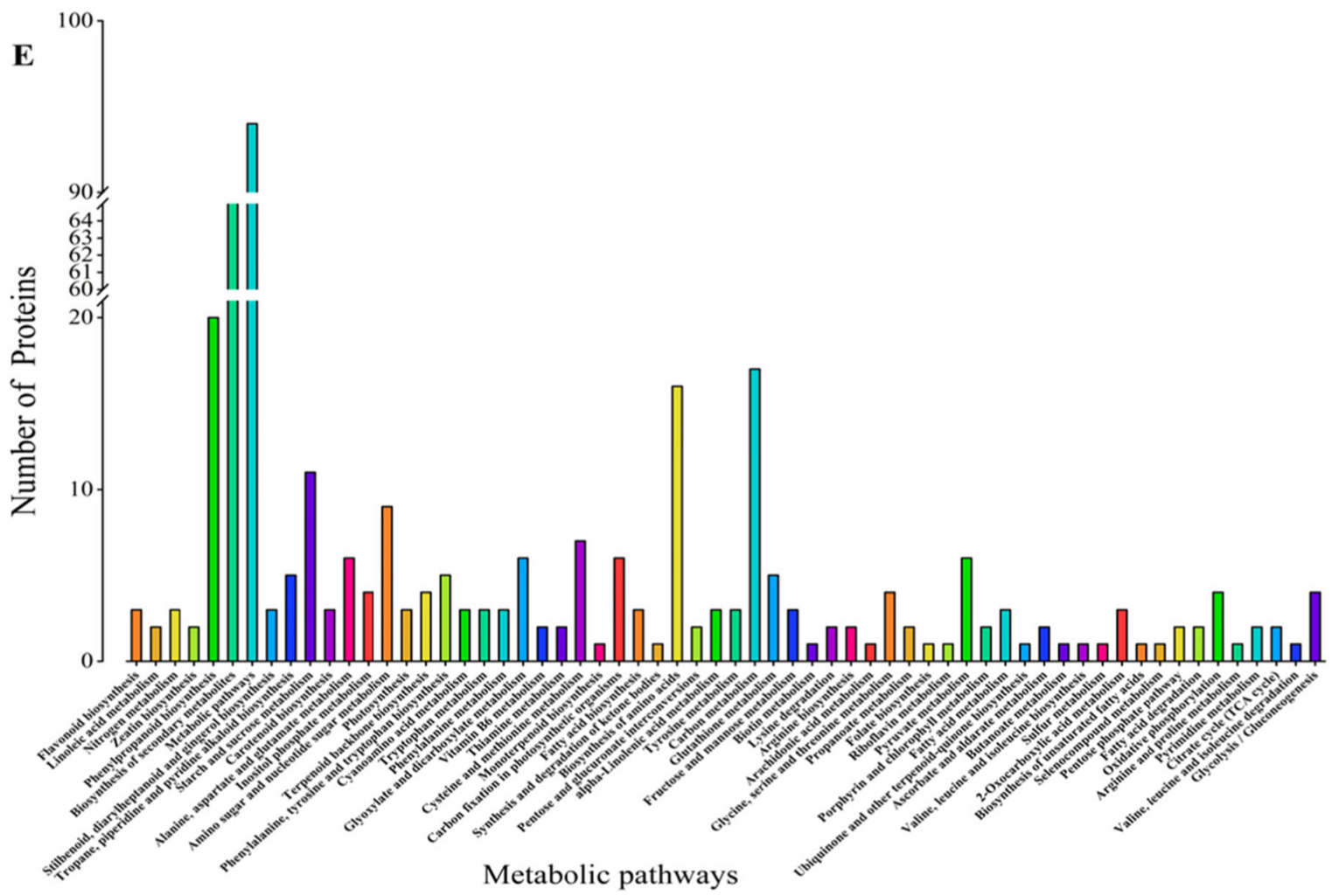

Fig. 4 Functional classification, subcellular localization and pathway affiliation of proteins. Identified proteins were categorized according to their gene ontology for their biological processes (a), cellular components (b), molecular functions (c), subcellular localizations (d) and association with different metabolic pathways (e) 
Table 2 Part of DEPs participated in phenylpropanoid biosynthesis

\begin{tabular}{ll}
\hline Differentially expressed proteins & $\boldsymbol{p}$ value \\
\hline Phenylalanine ammonia lyase & $5.6 \times 10^{-9}$ \\
Cinnamyl alcohol dehydrogenase & $4.3 \times 10^{-8}$ \\
Peroxidase 4 & $1 \times 10^{-32}$ \\
Cytochrome P450 & $3.7 \times 10^{-13}$ \\
4-coumarate-CoA ligase & $1.1 \times 10^{-16}$ \\
shikimate O-hydroxycinnamoyl transferase & $1 \times 10^{-32}$
\end{tabular}

Network of the differential metabolic compounds in glucosinolate biosynthesis

As previously mentioned, glucosinolate biosynthesis, comprised of amino acid such as leucine (Leu), tryptophan (Try), tyrosine (Tyr), isoleucine (Ile) and valine (Val), was significant in metabolic pathways for increasing the chilling tolerance of sweetpotato roots. The glucosinolate can be synthesized from methionine, branched-chain amino acids or aromatic amino acids process (Fig. 9). Leu, Ile and Val were involved in branched-chain amino acids. Try and Tyr were imperative for aromatic amino acids pathway. All these amino acids were significantly up-regulated in glucosinolate biosynthesis (Fig. 9).

\section{Discussion}

\section{ROS scavenging and osmotic adjustment substances}

The growth and productivity of higher plants are severely limited by environmental stresses including low- temperature, drought and salinity. MDA content and ion leakage are indicators of membrane damage caused by chilling stress. Gill et al. [19] described that excess ROS resulted in rise of MDA, membrane leakage and DNA breakdown which cause severe damage to plant cell. Plants have evolved in the presence of ROS and have acquired dedicated pathways to protect themselves against oxidative damage and fine modulation of low levels of ROS for signal transduction [20-24]. The enzymatic systems of ROS scavenging mechanisms mainly include SOD, POD, CAT and APX [25]. The expressions of intracellular genes $C u Z n S O D$ and $s w A P X 1$ were significantly correlated with low temperature stress $\left(4^{\circ} \mathrm{C}\right)[26]$. SOD is able to rapidly convert. $\mathrm{OH}$ to $\mathrm{H}_{2} \mathrm{O}_{2}$, and the generated $\mathrm{H}_{2} \mathrm{O}_{2}$ is then converted to water and dioxygen by CAT and APX [27-29]. However, abiotic stress resistance has been increased in rice mutants with double silenced for cytosolic APXs gene (APX1/2 s) [30]. In our research, L-ascorbate peroxidase 3 and catalase were down-regulated during $4{ }^{\circ} \mathrm{C}$ storage (Additional file 2), nevertheless the CAT/APX activities (Fig. 3b, c) were increased. This discrepancy between proteomic and biochemical data may be explained by higher $\mathrm{H}_{2} \mathrm{O}_{2}$ levels and increased ascorbate redox states, which enhanced the CAT/APX activity indirectly.

Induction of osmoprotectants biosynthesis is another type of the plant response to low temperature. Several studies suggested that increased abiotic stress tolerance was obtained by introducing simple metabolic traits from other organisms such as the production of

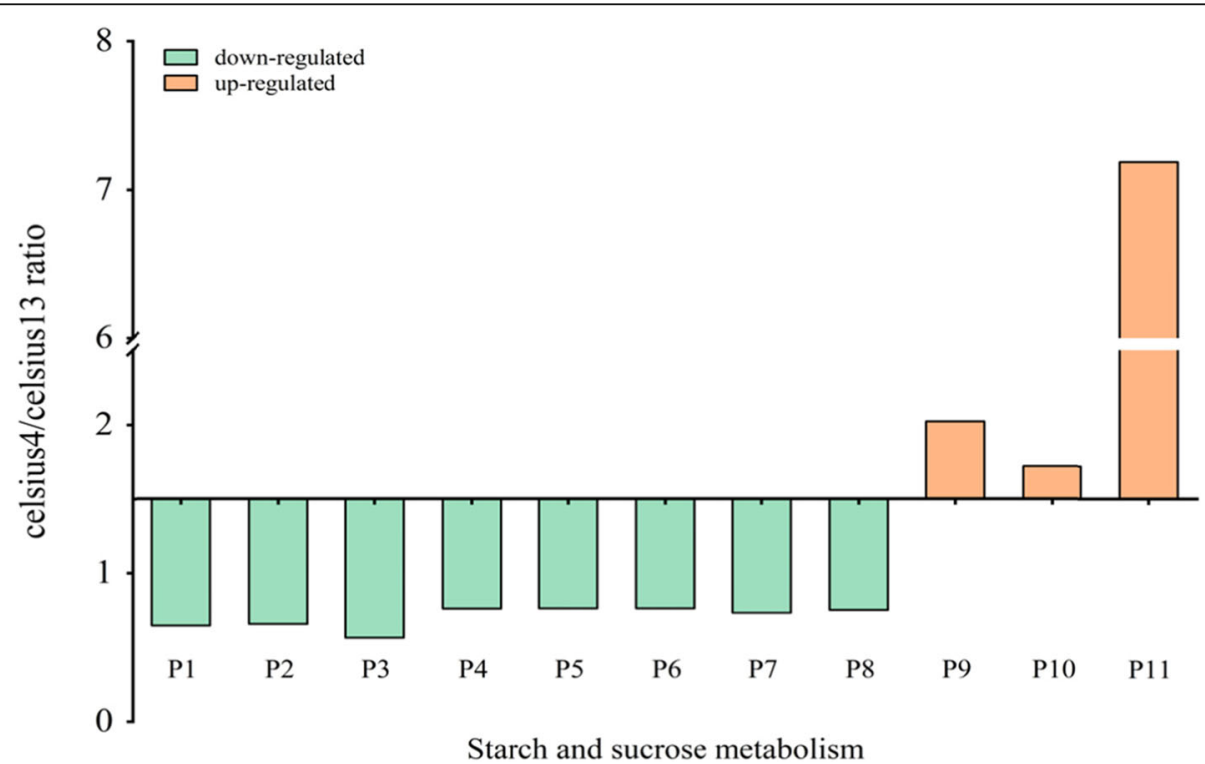

Fig. 5 Differential multiple of the differentially expressed proteins (DEP) participated in starch and metabolism. P1: Glucose-1-phosphate adenylyltransferase (large subunit); P2: $\beta$-xylosidase/a-arabinofuranosidase 2; P3: $\beta$-glucosidase 12; P4: Glucose-1-phosphate adenylyltransferase (small subunit); P5: Sucrose synthase 6; P6: Glucan endo-1,3- $\beta$-glucosidase 6; P7: 4-a-glucanotransferase; P8: Isoamylase 3; P9: $\alpha$-amylase; P10: Probable fructokinase 7; P11: Sucrose synthase 


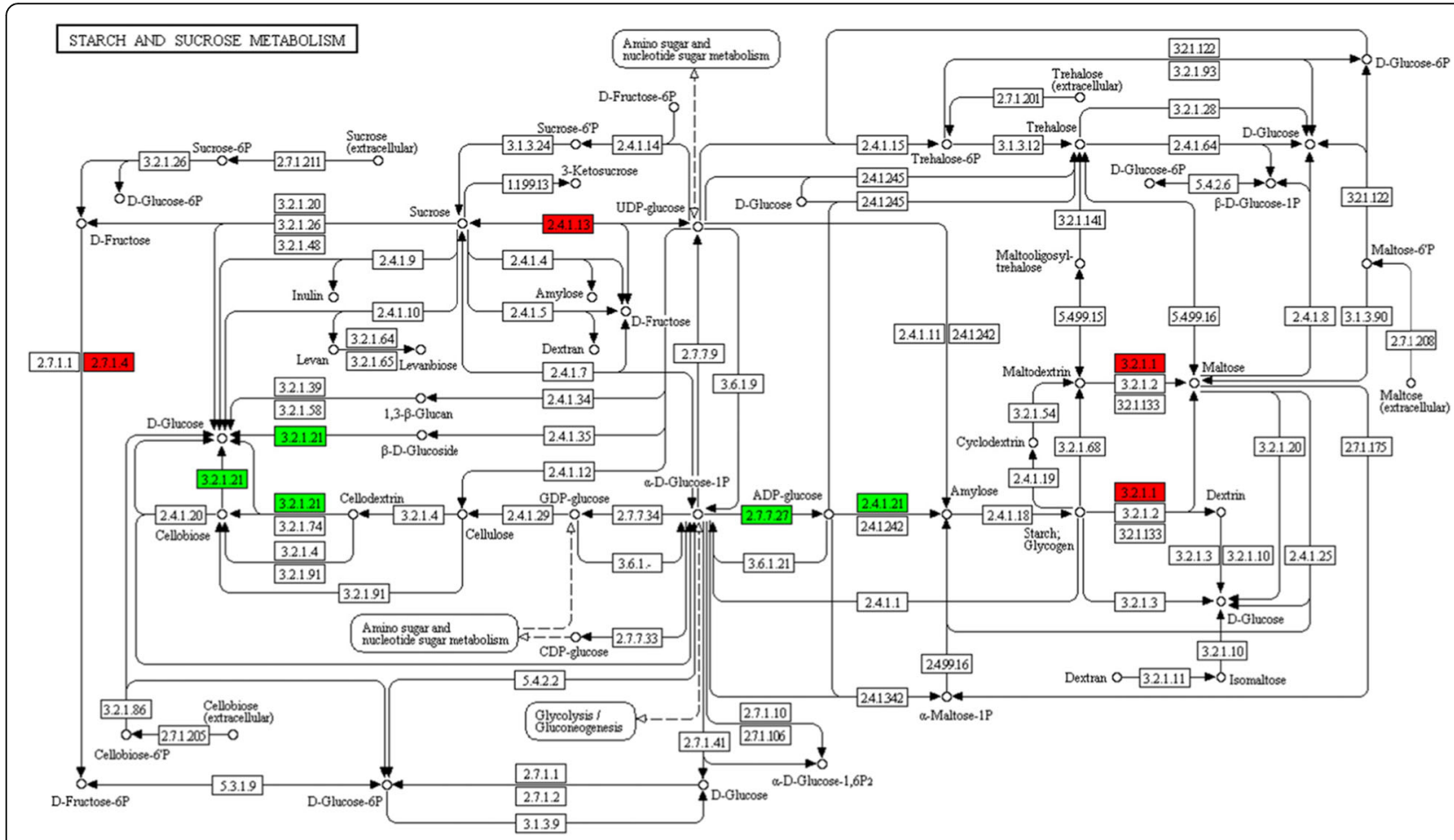

Fig. 6 Changes of differentially expressed proteins (DEPs) involved in starch and sucrose metabolism of sweetpotato roots under cold stress. The significantly up-(red) and down-regulated (green) expressed proteins are demonstrated. EC: 3.2.1.1, EC: 2.4.1.13 and EC: 2.7.1.4 proteins (red) were a-amylase, sucrose synthase and fructokinase, respectively. EC: 3.2.1.21, EC: 2.7.7.27 and EC: 2.4.1.21 proteins (green) were $\beta$-glucosidase, glucose-1phosphate adenylyl-transferase and starch synthase, respectively

trehalose and proline [31]. Recent data suggested that overexpression of DlICE1 (Dimocarpus longan L.) in transgenic Arabidopsis conferred enhanced cold tolerance via increased proline content and antioxidant enzyme such as SOD, CAT, APX [32]. In our research, the low temperature $\left(4{ }^{\circ} \mathrm{C}\right)$ significantly increased the activities of antioxidant enzymes (Fig. 3a, b, c), the producing rate of $\mathrm{O}_{2}^{-{ }^{-}}$(Fig. 3d) and proline content (Fig. 3e) as compared to the control $\left(13^{\circ} \mathrm{C}\right)$. Thus, less damage from membrane lipid peroxidation enabled the sweetpotato roots to continue normal metabolism under lowtemperature condition, contributing to their higher cold tolerance.

\section{The role of phenolics compounds and glucosinolate biosynthesis under abiotic stress}

Phenylpropanoids are a group of secondary metabolites synthesized from the amino acid phenylalanine [33, 34]. In plants, the phenylpropanoid pathway underlying abiotic stress tolerance is tightly connected with physiological and molecular mechanisms. Phenolic accumulation is usually activated when plants face multiple abiotic stresses [35]. Increased phenolic levels play crucial role in plants protection against chilling stress [36]. Gao et al. [37] confirmed that stimulated phenolic biosynthesis was owing to the enhanced expression of
PAL, CAD and HCT by carrying out the experiments with peach under low-temperature stress. In our research, the phenylpropanoid biosynthesis, a main metabolic pathway, were up-regulated by lots of proteins, especially HCT, PAL and CAD (Fig. 4e and Table 2). Thus, our results were consistent with the previeous research. More importantly, the roots decay was not found (Fig. 1 and Table 1) may be due to enhanced thickness of plant cell walls generated by phenolic accumulation, which is beneficial for the prevention of chilling injury $[38,39]$.

Glucosinolates mainly function as defense molecules [40]. They are also known as mustard oil glucosides. Until now, more than 100 glucosinolates have been found in plants. In terms of their precursor amino acids, glucosinolates can be categorized into indole glucosinolates, aliphatic glucosinolates and aromatic glucosinolates, which were derived from Trp, from Ala, Leu, Ile, $\mathrm{Val} / \mathrm{Met}$, and from Phe and Tyr, respectively [41]. These results were consistent with our research (Table 4 and Fig. 9). Previous studies demonstrated that the accumulation of glucosinolate biosynthetic intermediates can limit the production of phenylpropanoids in two Arabidopsis mutants of ref2 and ref5 [42, 43]. However, it seems that there was no obviously crosstalk between phenylpropanoids and glucosinolates biosynthesis. 


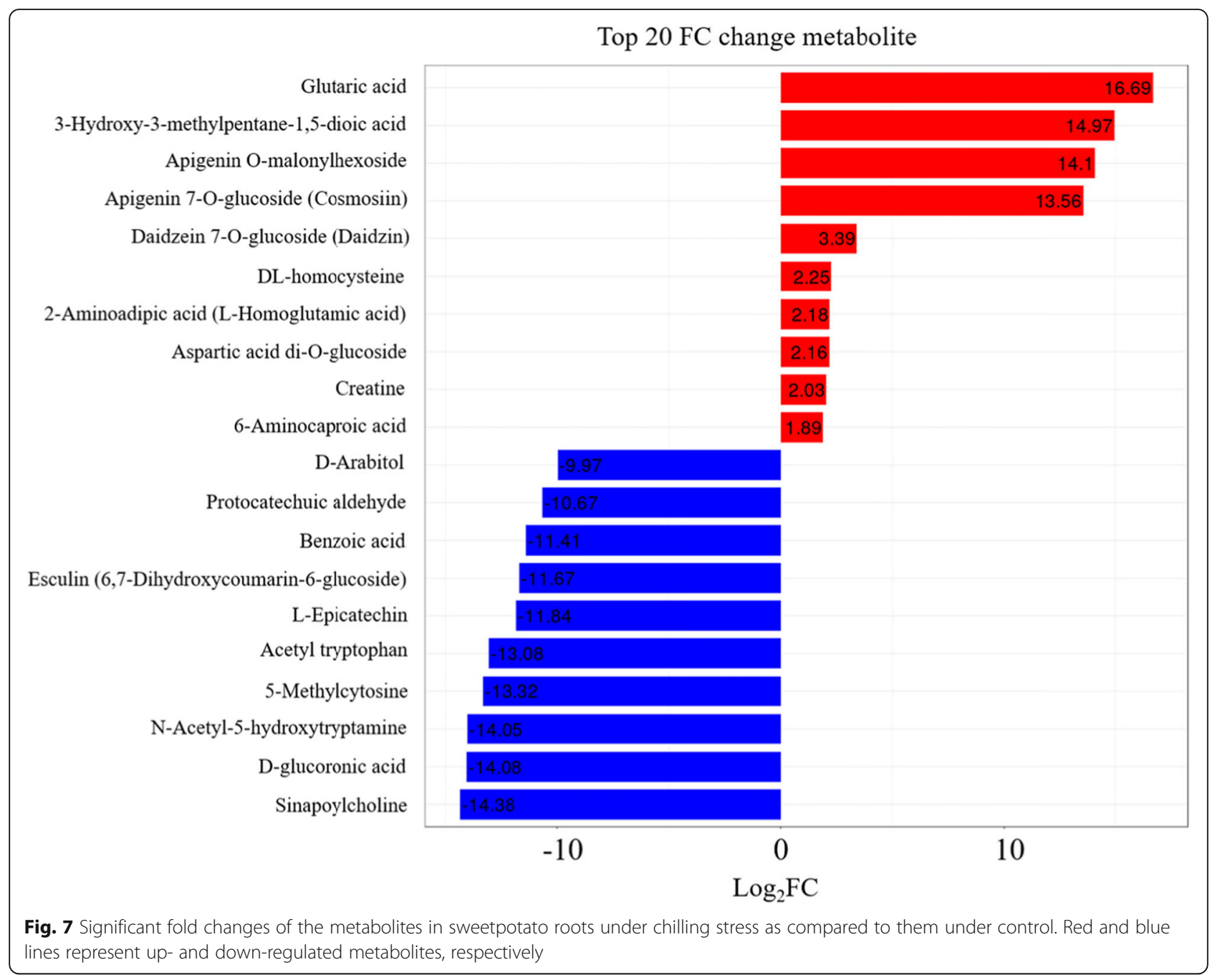

Table 3 Screening of differential expressed metabolic components

\begin{tabular}{|c|c|c|c|c|}
\hline Compounds & Class & VIP & $\log _{2} \mathrm{FC}$ & Type \\
\hline Glutaric acid & Organic acids & 4.01 & 16.69 & up \\
\hline D-glucuronic acid & Carbohydrates & 3.69 & 14.08 & down \\
\hline N-acetyl-5-hydroxytryptamine & Tryptamine derivatives & 3.66 & 14.05 & down \\
\hline 5-Methylcytosine & Nucleotide and its derivates & 3.58 & 13.32 & down \\
\hline Esculin & Coumarins & 3.26 & 11.67 & down \\
\hline 3-Hydroxy-3-methylpentane-1,5-dioic acid & Amino acid derivatives & 2.66 & 14.97 & up \\
\hline O-sinapoyl quinic acid & Quinate and its derivatives & 2.61 & 2.75 & down \\
\hline Acetyl tryptophan & Amino acid derivatives & 2.45 & 13.08 & down \\
\hline Sinapic acid & Hydroxycinnamoyl derivatives & 2.39 & 1.72 & down \\
\hline L-Epicatechin & Catechin derivatives & 2.35 & 11.84 & down \\
\hline Protocatechuic aldehyde & Catechin derivatives & 2.26 & 10.67 & down \\
\hline Pantetheine & Vitamins & 2.21 & 5.40 & down \\
\hline D-arabitol & Alcohols and polyols & 2.15 & 9.97 & down \\
\hline
\end{tabular}




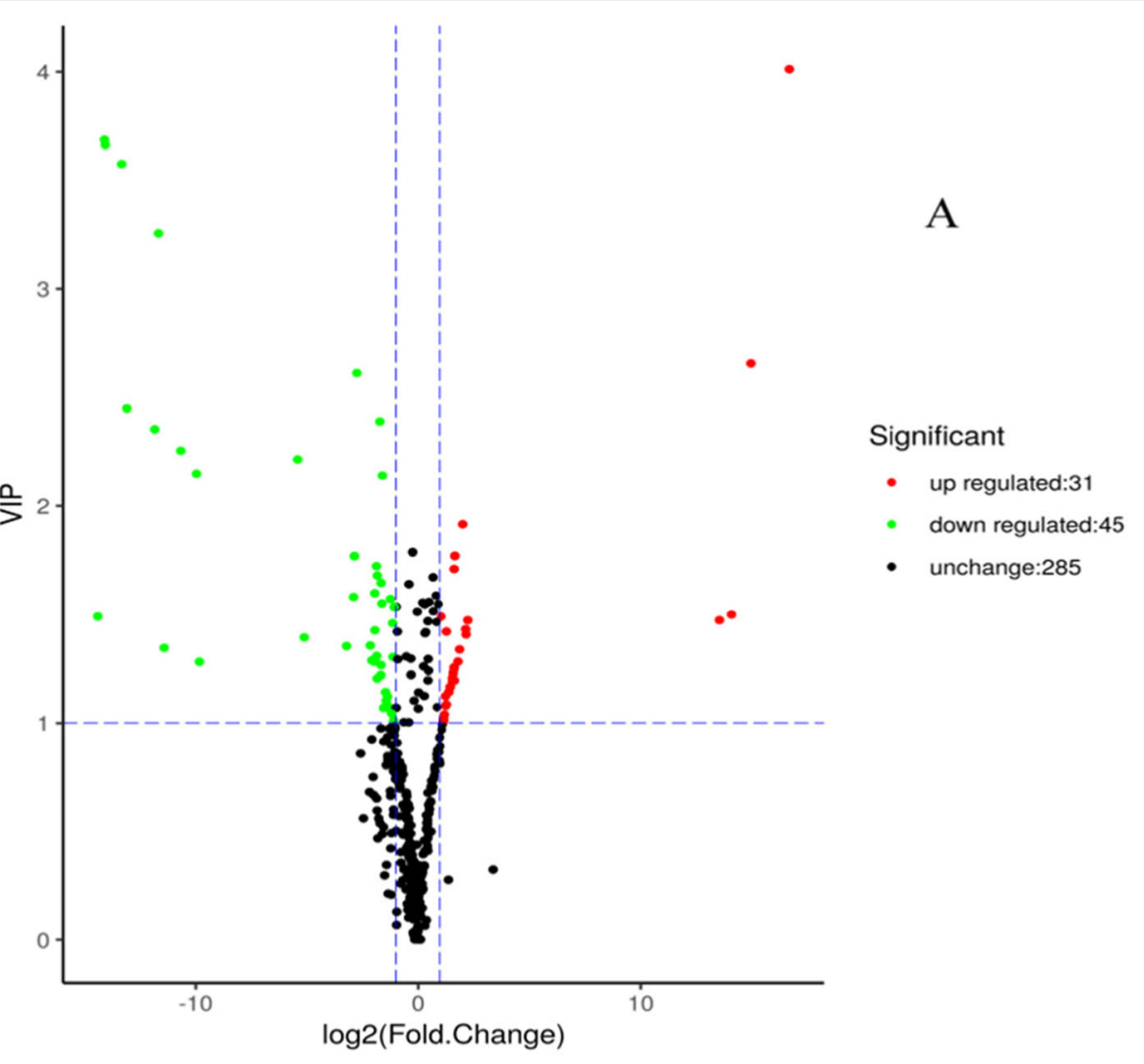

Statistics of KEGG Enrichment

Valine, leucine and isoleucine degradation Valine, leucine and isoleucine biosynthesis Tropane, piperidine and pyridine alkaloid biosynthesis Salmonella infection

Protein digestion and absorption Phenylalanine, tyrosine and tryptophan biosynthesis Phenylalanine metabolism Penicillin and cephalosporin biosynthesis Pantothenate and CoA biosynthesis Lysine degradation Glucosinolate biosynthesis Drug metabolism - other enzymes D-Arginine and D-ornithine metabolism Clavulanic acid biosynthesis Biosynthesis of secondary metabolites Biosynthesis of enediyne antibiotics Biosynthesis of alkaloids derived from shikimate pathway Biosynthesis of alkaloids derived from ornithine, lysine and nicotinic acid Aminoacyl-tRNA biosynthesis 2-Oxocarboxylic acid metabolism

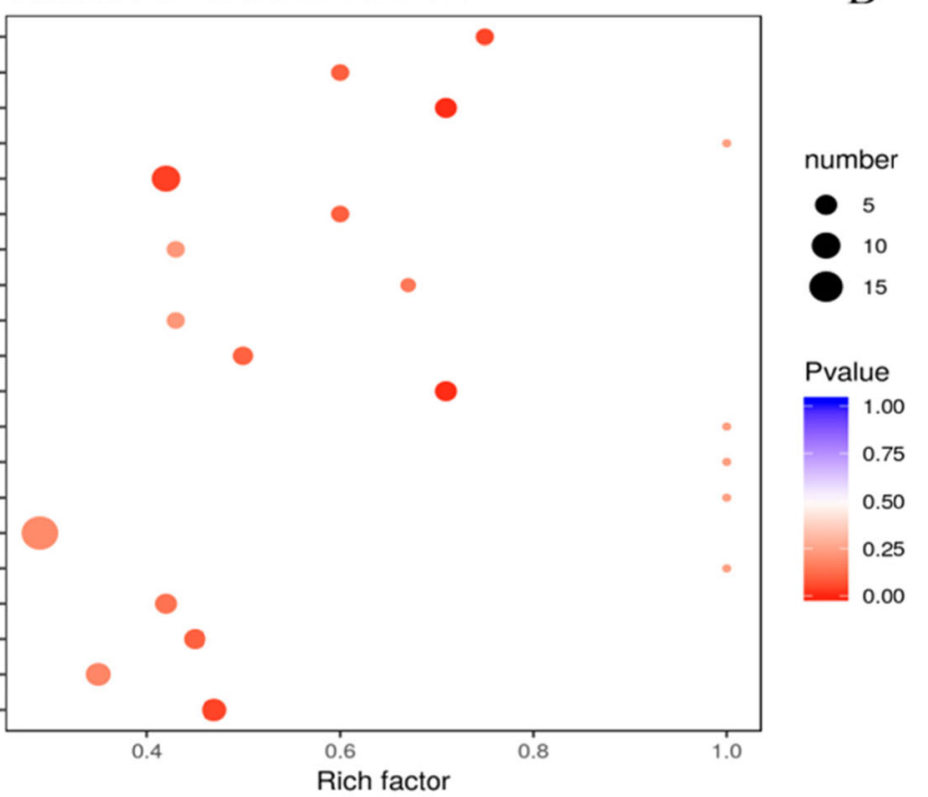

Fig. 8 The volcano plots and statistics of KEGG pathway enrichment of significantly differential expressed metabolites (DEMs) were demonstrated. In the volcano plots, red, green and black dots represent up-, down-regulated and insignificant changed metabolites, respectively (a). The dimension of dots indicates the amount of the DEMs. The color ( $P$-value) explained the significance of DEM. Rich factor means the ratio of the number of the DEMs to the total number of them detected in the corresponding pathway (b) 
Table 4 KEGG pathway enrichment of significantly DEMs

\begin{tabular}{lll}
\hline KEGG pathway enrichment & $\boldsymbol{P}$-value & Compounds \\
\hline glucosinolate biosynthesis & $9.94 \times 10^{-3}$ & Leu; Try; Tyr; lle; Val \\
tropane, piperidine and pyridine alkaloid biosynthesis & $9.94 \times 10^{-3}$ & Putrescine; piperidine; pipecolic acid; Ile; Lys \\
protein digestion and absorption & $3.56 \times 10^{-2}$ & Putrescine; piperidine; Indole; Val; lle; Tyr; Try; Arg; Lys; Leu \\
\hline
\end{tabular}

Abbreviation: Leu Leucine, Try Tryptophan, Tyr Tyrosine, Ile Isoleucine, Val Valine, Arg Arginine, Lys Lysine

\section{Sugar as antioxidants in sweetpotato roots}

Sweetpotato has been known as one of the highest starch producing crops due to their higher sink strength [44]. Soluble sugars were linked with the production rates of ROS by regulating its producing metabolic pathways, such as mitochondrial respiration or photosynthesis [45]. Starch content has significantly negative relationship with sucrose in tuber crops, because the catabolism of starch been impaired with respiratory rate decrease in low storage temperature. In our study, three types of soluble sugar contents were obviously increased (Fig. 3f). Moreover, $\alpha$-amylase, $\beta$-amylase, sucrose synthase and fructokinase were significantly up-regulated, which boosted the sweetness of the tuber roots under cold temperature (Figs. 5 and 6). These results confirmed that sweetness could enhance the chilling stress tolerance of sweetpotato roots.

Nevertheless, the concept 'sugar as antioxidant' has been put forward in recent years [46], and some genes encoding different sugar compounds were confirmed to enhance low temperature tolerance in petunia, tobacco and rice [47-51]. It is more and more recognized that water-soluble carbohydrates (glucose, fructose and sucrose) are regarded as key regulators in plant responses to abiotic/biotic stress. High antioxidant protection was maintained by an accumulation of increased soluble sugars under drought stress in Arabidopsis thaliana leaves [52]. In addition, low temperature can affect the metabolic activities and cause osmotic stress in plants. Cell turgor is able to be stabilized by soluble

GLUCOSINOLATE BIOSYNTHESIS
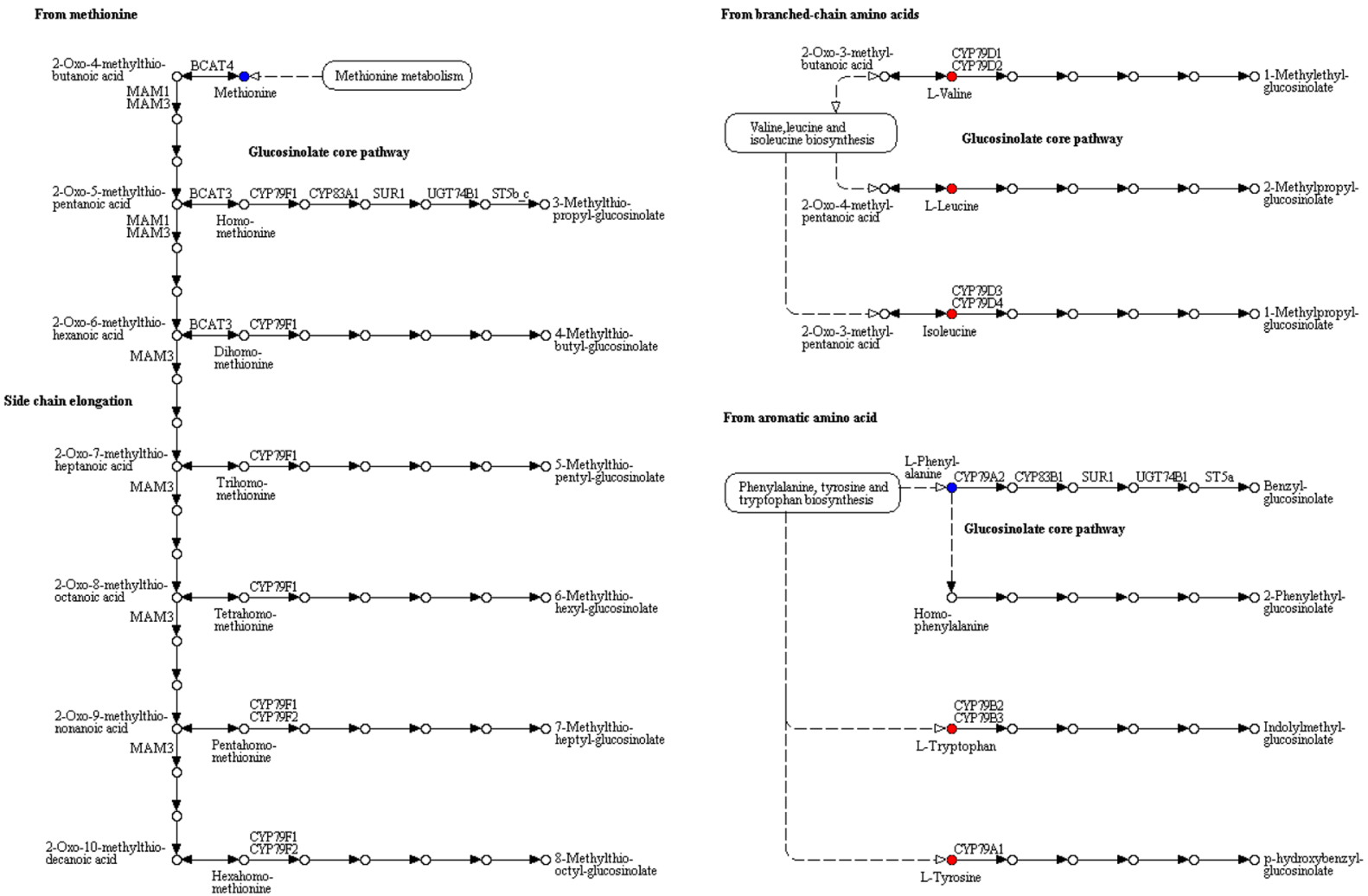

Fig. 9 Differential expressed metabolic components in glucosinolate biosynthesis. Red and blue dots represent up-regulated and insignificant changed compounds, respectively 
carbohydrates [53]. Hence, both simple sugars and polysaccharides are necessary for plant survival under stress conditions $[54,55]$.

\section{Conclusions}

In summary, our proteomic and metabolic profile analysis of sweetpotatoes reveal that the CI index, REC and MDA content in roots stored at $4{ }^{\circ} \mathrm{C}$ were much higher than them at $13^{\circ} \mathrm{C}$. Low-temperature storage condition significantly enhanced the activities of SOD, CAT, APX, $\mathrm{O}_{2}{ }^{--}$producing rate, proline and especially soluble sugar contents. Most of DEPs were implicated in pathways related to metabolic pathway, especially phenylpropanoids and followed by starch and sucrose metabolism. $\alpha-$ amylase, sucrose synthase and fructokinase were significantly up-regulated in starch and sucrose metabolism, while $\beta$-glucosidase, glucose-1-phosphate adenylyltransferase and starch synthase were opposite. Interestingly, there was discrepancy between proteomic (L-ascorbate peroxidase 3 and catalase) and biochemical (CAT/APX enzyme activity) data, which may be owing to higher $\mathrm{H}_{2} \mathrm{O}_{2}$ levels and increased glutathione and ascorbate redox states, which enhanced the CAT/APX activity indirectly. Moreover, glucosinolate biosynthesis played a leading role in metabolic pathways. Leucine, tryptophan, tyrosine, isoleucine and valine were all significantly up-regulated in glucosinolate biosynthesis. These results would expand our knowledge of the proteome and metabolome about the chilling tolerance of sweetpotatoes.

\section{Methods}

\section{Plant materials and storage condition}

Sweetpotatoes (I. batatas L. cv. Xinxiang), obtained from Zhejiang Academy of Agricultural Sciences of China (supplementary Table S1), were grown in the greenhouse at $25-30{ }^{\circ} \mathrm{C}$ under a long-day photoperiod $(16 / 8 \mathrm{~h}$, light/dark) according to standard agricultural practices in 2018. The mature roots (average weight 100-120 g) were selected with the same size. They had no physical injury or bacterial infection. Then, they were divided randomly into two groups with three replicates and stored in Temperature Humidity Chamber of $4{ }^{\circ} \mathrm{C}$ and $13{ }^{\circ} \mathrm{C}$ (CK) for 14 days, respectively (Laifu MJX-280H, China). After storage, the tubers were sliced to $1 \mathrm{~mm}$ thickness, put into liquid nitrogen and stored at $-80^{\circ} \mathrm{C}$ for further analysis [26].

\section{Estimation of chilling injury index}

The apparent condition of surface pitting, dark watery patches, and internal tissue browning were the typical CI symptoms of tuberous roots $[26,56]$. Ten roots for each replicate were chosen for $\mathrm{CI}$ evaluated visually. The $\mathrm{CI}$ index calculation was according to $\mathrm{Li}$ et al. [26].
Relative electrical conductivity and malondialdehyde content assays

The relative electrical conductivity (REC) was measured as previously described with some modification [57]. The REC calculation was according to $\mathrm{Hu}$ et al. [58]. The MDA content was determined by the thiobarbituric acid method [58].

\section{Determination of antioxidant enzyme, the rate of $\mathrm{O}_{2}{ }^{-}$ production and proline content}

For enzyme activities, the fresh roots $(0.1-0.5 \mathrm{~g})$ were homogenized in $10 \mathrm{ml}$ of $50 \mathrm{mM}$ precooled potassium phosphate buffer (PBS; pH 7.8) under ice cold conditions [59]. Superoxide anions $\left(\mathrm{O}_{2}{ }^{-}\right)$producing rate was determined according to Jiang \& Zhang [60] with some modifications. Superoxide dismutase (SOD), catalase (CAT) and ascorbate peroxidase (APX) activity was determined according to Dhindsa \& Matowe [61], Aebi [62], and Nakano \& Asada [63], respectively. Proline content was measured according to Bates et al. [64].

\section{Determination of soluble sugar composition}

High performance liquid chromatography (HPLC) was used to determine the composition of soluble sugars (glucose, fructose and sucrose) in roots. The procedure of HPLC was in terms of Li et al. [26].

\section{Protein extraction and 1-DE SDS-PAGE}

The flesh of sweetpotato was grinded by liquid nitrogen into fine powder and four volumes of lysis buffer $(8 \mathrm{M}$ urea, $1 \%$ Triton-100, $10 \mathrm{mM}$ dithiothreitol and 1\% Protease Inhibitor Cocktail) were added to sonication extract three times on ice using a high intensity ultrasonic processor. The ultrasonic time was $3 \mathrm{~s}$ of ultrasound and $6 \mathrm{~s}$ of pause, with a total of 20 cycles. The electrophoresis of protein samples was performed with 12\% SDS PAGE gels and stained by Coomassie Blue R-250.

\section{LC-MS/MS of digested peptides}

The tryptic peptides were loaded onto a home-made reversed-phase analytical column $(15 \mathrm{~cm}$ length, $75 \mu \mathrm{m}$ i.d.). The digested peptide was subjected to NSI source followed by tandem mass spectrometry (LC-MS/MS) in Q Exactive ${ }^{\text {tm }}$ Plus (Thermo Scientific). Peptides were then selected for MS/MS using NCE set as 28 and the fragments were detected at a resolution of 17,500 in the Orbitrap [65].

\section{Database searching of proteins}

The MS/MS data generated were processed using Maxquant search engine (v.1.5.2.8) in uniport Toxoplasma gondii database. Tandem mass spectra were searched against Vert_tom_20141002 database (117,248 entries). Carbamidomethyl on Cysteine was specified as fixed 
modification and oxidation on Met was specified as variable modifications [66].

\section{Bioinformatics analysis}

The Gene Ontology (GO) annotation proteome was derived from the UniProt-GOA database (http://www.ebi. ac.uk/GOA/). Identified proteins domain functional description were annotated by InterProScan (http://www. ebi.ac.uk/interpro/) based on protein sequence alignment method used InterPro domain database. The KEGG (Kyoto Encyclopedia of Genes and Genomes) database was used to annotate protein pathway. Localization of proteins was predicted with wolfpsort software (PSORT/PSORT II). For functional enrichment, a two-tailed Fisher's exact test was conducted to test the enrichment of the DEPs against all identified proteins.

\section{Metabolome profiling of tubers}

The tubers sliced to $1 \mathrm{~mm}$ thickness was crushed using a mixer mill (MM400, Retsch) with a zirconia bead for 1.5 min at $30 \mathrm{~Hz} .100 \mathrm{mg}$ flesh powder was extracted overnight at $4{ }^{\circ} \mathrm{C}$ with $1.0 \mathrm{ml} 70 \%$ aqueous methanol. The sample extracts were analyzed using an LC-ESI-MS/MS system (HPLC, Shim-pack UFLC SHIMADZU CBM30A, MS, Applied Biosystems 6500 Q TRAP). The metabolomics approach was according to Yan et al. [67] with some modification.

\section{Protein and metabolite data analysis}

Each metabolite was searched on metware database (MWDB) (https://www.metware.cn). PubChem (https:// pubchem.ncbi.nlm.nih.gov/) was used for their classifications. Significance analysis of possible comparisons ( $p$ value) were tested at $p<0.05$. The Filtered $p$ value matrix transformed by the function $\mathrm{x}=-\lg$ ( $p$ value) was used to evaluate the ratio of celesius4 to celesius13, which was positively correlated with the expression multiple of the DEP $(x>1.5)$. The analysis of variance and mean separation of all metabolites were performed with Analyst 1.6.1, Partial Least Squares-Discriminant Analysis (PLS-DA) and Orthogonal Partial Least SquaresDiscriminant Analysis (OPLS-DA) model. Figures were drawn by origin 2018 .

\section{Supplementary information}

Supplementary information accompanies this paper at https://doi.org/10. 1186/s12870-020-02642-7.

Additional file 1. The peptides information of proteins identified in $/$. batata roots stored at $4^{\circ} \mathrm{C}$ compared to tubers under $13^{\circ} \mathrm{C}(\mathrm{CK})$ were subjected to NSI source followed by tandem mass spectrometry (MS/MS) in Q ExactiveTM Plus (Thermo) coupled online to the UPLC.

Additional file 2. Protein description of DEPs in I. batata roots by $>1.5$ fold.
Additional file 3. Functional classification of Gene ontology (GO) annotation of 1 . batata proteins. Proteins were assigned into three categories: biological process, cellular components and molecular functions.

Additional file 4. Subcellular location of differentially expressed proteins (DEPs) identified by $>1.5$ fold in 1 . batata roots under cold stress $\left(4^{\circ} \mathrm{C}\right)$ compared to CK.

Additional file 5. KEGG annotations of DEPs in I. batata roots under cold stress $\left(4^{\circ} \mathrm{C}\right)$ compared to $\mathrm{CK}$.

Additional file 6. Differentially expressed metabolites (DEMs) information in 1. batata roots under cold stress $\left(4^{\circ} \mathrm{C}\right)$ compared to $\mathrm{CK}$.

Additional file 7: Table S1. Information of sweetpotato materials. Table S2. Information of differentially expressed proteins. Table S3. Number of differentially expressed metabolisms. Figure S1. SDS-PAGE of total proteins extracted from root tuber of Ipomoea batatas L.. (30 $\mu \mathrm{g}$ total proteins each lane). Figure S2. Distribution of proteins according to molecular weights.

\section{Abbreviations}

APX: Ascorbate peroxidase; Arg: Arginine; CAD: Cinnamyl alcohol dehydrogenase; CAT: Catalase; Cl: Chilling injury; DEMs: Differentially expressed metabolites; DEPs: Differentially expressed proteins; FC: Fold change; GO: Gene Ontology; HCT: Hydroxycinnamoyl transferase; Ile: Isoleucine; KEGG: Kyoto Encyclopedia of Genes and Genomes; Leu: Leucine; Lys: Lysine; MWDB: Metware database; OPLS-DA: Orthogonal Partial Least Squares-Discriminant Analysis; PAL: Phenylalanine ammonia lyase; PLS-DA: Partial Least Squares-Discriminant Analysis; ROS: Reactive oxygen species; $\mathrm{O}_{2}$ : Superoxide anions; SOD: Superoxide dismutase; Try: Tryptophan; Tyr: Tyrosine; Val: Valine; VIP: Variable Importance in Project

\section{Acknowledgements}

We are thankful to Prof. Liehong Wu who kindly provided the sweetpotato cultivar 'Xinxiang' used as material in our experiment.

\section{Authors' contributions}

PC and HY conceived the research plan, analysed the data and wrote the manuscript. CC and YH did the sugar content analysis. YL and GL performed antioxidant enzymes measurements. All authors read and approved this final version of manuscript.

\section{Funding}

This work was supported by the National Natural Science Foundation of China (31871857, HQ Yang), Zhejiang Provincial Natural Science Foundation of China (LY19C200015, HQ Yang), The National Special (Root crops) Industry Technology System of China (CARS-10-B19, GQ Lu) and the Scientific Research Fund of Zhejiang A\&F University (2017FR026, P Cui). The funders played no role in designing the study, analysis, interpretation of data and writing the manuscript.

\section{Availability of data and materials}

The datasets generated during the current study are available in the PRIDE partner repository with the accession number PXD017728, https://www.ebi. ac.uk/pride/login, and they are available from the corresponding author upon reasonable request (Huqing Yang, yanghuqing@sohu.com).

Ethics approval and consent to participate

The voucher specimen of sweetpotato was deposited in Zhejiang Academy of Agricultural Sciences. Their taxon, variety, voucher, geographic origin and identifier were listed in Supplementary Table S1.

Consent for publication

Not applicable.

Competing interests

The authors declare that they have no competing interests. 
Received: 16 December 2019 Accepted: 9 September 2020

\section{Published online: 21 September 2020}

\section{References}

1. Scott GJ, Rosegrant MW, Ringler C. Global projections for root and tuber crops to the year 2020. Food Policy. 2000;25:561-97.

2. Tumwegamire $S$, Kapinga R, Rubaihayo PR, Labonte DR, Grüneberg WJ, Burgos $\mathrm{G}$, et al. Evaluation of dry matter, protein, starch, sucrose, $\beta$-carotene, iron, zinc, calcium, and magnesium in east African sweetpotato [lpomoea batatas (L.) lam] germplasm. HortScience. 2011;46:348-57.

3. Masuda D, Fukuoka N, Goto H, Kano Y. Effect of cold treatment after harvest on sugar contents and storability in sweet potato (Ipomoea batatas L.). Horticult Res. 2007;6:597-601.

4. Li R, Zhai H, Kang C, Liu D, He S, Liu Q. De novo transcriptome sequencing of the orange-fleshed sweet potato and analysis of differentially expressed genes related to carotenoid biosynthesis. Int J Genomics. 2015;2015:802-12.

5. Wang Z, Fang B, Chen J, Zhang X, Luo Z, Huang L, et al. De novo assembly and characterization of root transcriptome using illumina paired-end sequencing and development of cSSR markers in sweetpotato (Ipomoea batatas). BMC Genomics. 2010;11:726.

6. Lee JJ, Park KW, Kwak Y-S, Ahn JY, Jung YH, Lee B-H, et al. Comparative proteomic study between tuberous roots of light orange- and purplefleshed sweetpotato cultivars. Plant Sci. 2012;193-194:120-9.

7. Lee JJ, Kim YH, Kwak YS, An JY, Kim PJ, Lee BH, et al. A comparative study of proteomic differences between pencil and storage roots of sweetpotato (Ipomoea batatas (L.) lam.). Plant Physiol Biochem. 2015;87:92-101.

8. Jiang Y, Chen C, Tao X, Wang J, Zhang Y. A proteomic analysis of storage stress responses in Ipomoea batatas (L.) lam. Tuberous root. Mol Biol Rep. 2012;39:8015-25.

9. Shekhar S, Mishra D, Buragohain AK, Chakraborty S, Chakraborty N. Comparative analysis of phytochemicals and nutrient availability in two contrasting cultivars of sweetpotato (Ipomoea batatas L.). Food Chem. 2015: 173:957-65.

10. Suntres ZE. Role of antioxidants in paraquat toxicity. Toxicology. 2002;180: 65-77.

11. Frohnmeyer $H$, Staiger D. Ultraviolet-B radiation-mediated responses in plants. Balancing damage and protection. Plant Physiol. 2003;133:1420-8.

12. Suzuki N, Mittler R. Reactive oxygen species and temperature stresses: a delicate balance between signalling and destruction. Physiol Plantarum. 2006;126:45-51.

13. Torres MA, Jones JDG, Dangl JL. Reactive oxygen species signaling in response to pathogens. Plant Physiol. 2006;141:373-8.

14. Sharma SS, Dietz KJ. The relationship between metal toxicity and cellular redox imbalance. Trends Plant Sci. 2009;14:43-50.

15. Bolouri-Moghaddam MR, Le Roy K, Xiang L, Rolland F, Van den Ende W. Sugar signalling and antioxidant network connections in plant cells. FEBS J. 2010;277:2022-37.

16. Miller G, Suzuki N, Ciftci-Yilmaz S, Mittler R. Reactive oxygen species homeostasis and signalling during drought and salinity stresses. Plant Cell Environ. 2010;33:453-67.

17. Mittler R. Oxidative stress, antioxidants and stress tolerance. Trends Plant Sci. 2002:7:405-10.

18. Gill SS, Tuteja N. Reactive oxygen species and antioxidant machinery in abiotic stress tolerance in crop plants. Plant Physiol Bioch. 2010;48:909-30

19. Gill RA, Zang LL, Ali B, Faroog MA, Cui P, Yang S, et al. Chromium-induced physio-chemical and ultrastructural changes in four cultivars of Brassica napus L. Chemosphere. 2015;120:154-64.

20. Choudhury FK, Rivero RM, Blumwald E, Mittler R. Reactive oxygen species, abiotic stress and stress combination. Plant J. 2017;90:856-67.

21. Foyer CH, Noctor G. Redox signalling in plants. Antioxid Redox Signal. 2013; 18:2087-90.

22. Considine MJ, Sandalio LM, Foyer $\mathrm{CH}$. Unravelling how plants benefit from ROS and NO reactions, while resisting oxidative stress. Ann Bot. 2015;116: 469-73.

23. Dietz KJ. Efficient high light acclimation involves rapid processes at multiple mechanistic levels. J Exp Bot. 2015;66:2401-14

24. Mignolet-Spruyt L, Xu E, Idanheimo N, Hoeberichts FA, Muhlenbock P, Brosche $M$, et al. Spreading the news: subcellular and organellar reactive oxygen species production and signalling. J Exp Bot. 2016;67:3831-44.

25. Apel K, Hirt H. Reactive oxygen species: metabolism, oxidative stress, and signal transduction. Annu Rev Plant Biol. 2004;55:373-99.
26. Li X, Yang HQ, Lu GQ. Low-temperature conditioning combined with cold storage inducing rapid sweetening of sweetpotato tuberous roots (Ipomoea batatas (L.) Lam) while inhibiting chilling injury. Postharvest Biol Technol. 2018;142:1-9.

27. Gechev TS, Van Breusegem F, Stone JM, Denev I, Laloi C. Reactive oxygen species as signals that modulate plant stress responses and programmed cell death. Bioessays. 2006;28:1091-101.

28. Mittler R. ROS are good. Trends Plant Sci. 2017;22:11-9.

29. You J, Chan Z. ROS regulation during abiotic stress responses in crop plants. Front Plant Sci. 2015;6:1092.

30. Bonifacio A, Martins MO, Ribeiro CW, Fontenele AV, Carvalho FE, MargisPinheiro $\mathrm{M}$, et al. Role of peroxidases in the compensation of cytosolic ascorbate peroxidase knockdown in rice plants under abiotic stress. Plant Cell Environ. 2011;34:1705-22.

31. Yang XY, Wang $R$, Hu QL, Li SL, Mao XD, Jing HH, et al. DIICET, a stressresponsive gene from Dimocarpus longan, enhances cold tolerance in transgenic Arabidopsis. Plant Physiol Bioch. 2019;142:490-9.

32. Bonawitz ND, Chapple $C$. The genetics of lignin biosynthesis: connecting genotype to phenotype. Annu Rev Genet. 2010;44:337-63.

33. Vanholme R, Cesarino I, Rataj K, Xiao Y, Sundin L, Goeminne G, et al. Caffeoyl shikimate esterase (CSE) is an enzyme in the lignin biosynthetic pathway in Arabidopsis. Science. 2013;341:1103-6.

34. Vanholme R, Storme V, Vanholme B, Sundin L, Christensen JH, Goeminne G, et al. A systems biology view of responses to lignin biosynthesis perturbations in Arabidopsis. Plant Cell. 2012;24:3506-29.

35. Sharma A, Shahzad B, Rehman A, Bhardwaj R, Landi M, Zheng BS. Response of phenylpropanoid pathway and the role of polyphenols in plants under abiotic stress. Molecules. 2019;24:1-22.

36. Zhou P, Li Q, Liu G, Xu N, Yang Y, Zeng W, et al. Integrated analysis of transcriptomic and metabolomic data reveals critical metabolic pathways involved in polyphenol biosynthesis in Nicotiana tabacum under chilling stress. Funct Plant Biol. 2018:46:30-43.

37. Gao H, Zhang Z, Lv X, Cheng N, Peng B, Cao W. Effect of 24-epibrassinolide on chilling injury of peach fruit in relation to phenolic and proline metabolisms. Postharvest Bio Tec. 2016;111:390-7.

38. Griffith M, Yaish MW. Antifreeze proteins in over wintering plants: a tale of two activities. Trends Plant Sci. 2004;9:399-405.

39. Naikoo Ml, Dar Ml, Raghib F, Jaleel H, Ahmad B, Raina A, et al. Role and regulation of plants phenolics in abiotic stress tolerance: an overview. In plant signalling molecules. Amsterdam: Elsevier; 2019. p. 157-68.

40. Halkier BA, Gershenzon J. Biology and biochemistry of glucosinolates. Annu Rev Plant Biol. 2006:57:303-33.

41. Brown PD, Tokuhisa JG, Reichelt M, Gershenzon J. Variation of glucosinolate accumulation among different organs and developmental stages of Arabidopsis thaliana. Phytochemistry. 2003;62:471-81.

42. Hemm MR, Ruegger MO, Chapple C. The Arabidopsis ref2 mutant is defective in the gene encoding CYP83A1 and shows both phenylpropanoid and glucosinolate phenotypes. Plant Cell. 2003;15:179-94.

43. Kim Jl, Dolan WL, Anderson NA, Chapple C. Indole glucosinolate biosynthesis limits phenylpropanoid accumulation in Arabidopsis thaliana. Plant Cell. 2015;27:1529-46.

44. Shekhar S, Mishra D, Gayali S, Buragohain AK, Chakraborty S, Chakraborty N. Comparison of proteomic and metabolomic profiles of two contrasting ecotypes of sweetpotato (Ipomoea batata L.). J Proteome. 2016;143:306-17.

45. Couée I, Sulmon C, Gouesbet G, El Amrani A. Involvement of soluble sugars in reactive oxygen species balance and responses to oxidative stress in plants. J Exp Bot. 2006;57:449-59.

46. Bolouri-Moghaddam MR, Le Roy K, Xiang L, Rolland F, Van den Ende W. Sugar signaling and antioxidant network connections in plant cells. FEBS J. 2010;277:2022-37.

47. Pennycooke JC, Jones ML, Stushnoff C. Down-regulating a-galactosidase enhances freezing tolerance in transgenic petunia. Plant Physiol. 2003;133: 901-9.

48. Chiang YJ, Stushnoff C, MCSay AE. Overexpression of mannitol-1-phosphate dehydrogenase increases mannitol accumulation and adds protectionagainst chilling injury in petunia. J Am Soc Hortic Sci. 2005;130: 605-10

49. Parvanova D, Popova A, Zaharieva I, Lambrev P, Konstantinova T, Taneva S, et al. Low temperature tolerance of tobacco plants transformed to accumulate proline, fructans, or glycine betaine. Variable chlorophyl fluorescence evidence. Photosynthetica. 2004;42:179-85. 
50. Li HJ, Yang AF, Zhang XC, Gao F, Zhang JR. Improving freezing tolerance of transgenic tobacco expressing sucrose: sucrose 1-fructosyltransferase gene from Lactucasativa. Plant Cell Tissue Organ Cult. 2007;89:37-48.

51. Kawakami A, Sato Y, Yoshida M. Genetic engineering of rice capable of synthesizing fructans and enhancing chilling tolerance. J Exp Bot. 2008;59: 793-802.

52. Sperdouli I, Moustakas M. Interaction of proline, sugars, and anthocyanins during photosynthetic acclimation of Arabidopsis thaliana to drought stress. J Plant Physiol. 2012;169:577-85.

53. Peshev D, Van den Ende W. Sugars as antioxidants in plants. In: Crop improvement under adverse conditions. Berlin: Springer-Verlag; 2013. p. 285-308.

54. Keunen E, Peshev D, Vangronsveld J, Ende WVD, Cuypers A. Plant sugars are crucial players in the oxidative challenge during abiotic stress: extending the traditional concept. Plant Cell Environ. 2013:36:1242-55.

55. Valluru R, Van den Ende W. Plant fructans in stress environments: emerging concepts and future prospects. J Exp Bot. 2008;59:2905-16.

56. Picha DH. Chilling injury, respiration, and sugar changes in sweet potatoes stored at low temperature. J Am Soc Hortic Sci. 1987;112:497-502.

57. Cao WH, Liu J, He XJ, Mu RL, Zhou HL, Chen SY, et al. Modulation of ethylene responses affects plant salt-stress responses. Plant Physiol. 2007; 143:707-19.

58. Hu TX, Wang YQ, Wang QQ, Dang NN, Wang L, Liu CC, et al. The tomato 2oxoglutarate-dependent dioxygenase gene SIF3HL is critical for chilling stress tolerance. Hortic Res. 2019;6:45.

59. Cui Y, Wang Q. Physiological responses of maize to elemental Sulphur and cadmium stress. Plant Soil Environ. 2006;52:523-9.

60. Jiang $\mathrm{M}$, Zhang J. Effect of abscisic acid on active oxygen species, antioxidative defence system and oxidative damage in leaves of maize seedlings. Plant Cell Physiol. 2001:42:1265-73.

61. Dhindsa SR, Matowe W. Drought tolerance in two mosses: correlated with enzymatic defence against lipid peroxidation. J Exp Bot. 1981;32:79-91.

62. Aebi H. Catalase in vitro. Methods Enzymol. 1984;105:121-6.

63. Nakano Y, Asada K. Hydrogen-peroxide is scavenged by ascorbate-specific peroxidase in spinach-chloroplasts. Plant Cell Physiol. 1981;22:867-80.

64. Bates $L$, Waldren $R$, Teare I. Rapid determination of free proline for water stress studies. Plant Soil. 1973:39:205-7.

65. Zhang L, Wang LN, Liang YC, Yu JF. FgPEX4 is involved in development, pathogenicity, and cell wall integrity in Fusarium graminearum. Curr Genet. 2019;65:747-58

66. Lu X, Luan S, Dai P, Meng XH, Cao BX, Luo K. iTRAQ-based comparative proteome analysis for molecular mechanism of defense against acute ammonia toxicity in Pacific white shrimp Litopenaeus vannamei. Fish Shellfish Immun. 2018;74:52-61.

67. Yan N, Du YM, Liu XM, Chu MJ, Shi J, Zhang HB, et al. A comparative UHPLC-QqQ-MS-based metabolomics approach for evaluating Chinese and north American wild rice. Food Chem. 2019;275:618-27.

\section{Publisher's Note}

Springer Nature remains neutral with regard to jurisdictional claims in published maps and institutional affiliations.

Ready to submit your research? Choose BMC and benefit from:

- fast, convenient online submission

- thorough peer review by experienced researchers in your field

- rapid publication on acceptance

- support for research data, including large and complex data types

- gold Open Access which fosters wider collaboration and increased citations

- maximum visibility for your research: over $100 \mathrm{M}$ website views per year

At $\mathrm{BMC}$, research is always in progress.

Learn more biomedcentral.com/submissions 